\title{
Staphylococcus aureus infective endocarditis: role of transoesophageal echocardiography
}

\author{
William Kogler, ${ }^{1}$ Michael Omar $(1),{ }^{2}$ Dominika Zoltowska, ${ }^{3}$ Srinivasan Sattiraju ${ }^{4}$
}

${ }^{1}$ Internal Medicine, UF Health Jacksonville, Jacksonville, Florida, USA

${ }^{2}$ Internal Medicine, University of Florida College of Medicine, Jacksonville, Florida, USA

${ }^{3}$ Cardiology, UF Health Jacksonville, Jacksonville, Florida, USA

${ }^{4}$ Cardiology, University of Florida College of Medicine, Jacksonville, Florida, USA

\section{Correspondence to} DrWilliam Kogler; william.kogler@jax.ufl.edu

Accepted 15 July 2020

\section{Check for updates}

(C) BMJ Publishing Group Limited 2020. No commercial re-use. See rights and permissions. Published by BMJ.

To cite: Kogler W, Omar M, Zoltowska D, et al. BMJ Case Rep 2020;13:e236530. doi:10.1136/bcr-2020236530

\section{DESCRIPTION}

A 66-year-old woman with a history of end-stage chronic obstructive pulmonary disease, obesity and no known prior cardiac condition, presented to the hospital with working diagnosis of septic shock. She was admitted to the intensive care unit for mechanical ventilation and vasopressor support. Two sets of blood cultures resulted positive for methicillin sensitive staphylococcus aureus (MSSA) for which intravenous nafcillin was initiated. CT of the head revealed multiple hypodense lesions, with subsequent $\mathrm{CT}$ of the abdomen revealing wedge-shaped infarct areas in the spleen and kidneys (figure 1). Transthoracic echocardiogram (TTE) was obtained which showed preserved left ventricular ejection fraction and no significant valvular dysfunction. However, this was a technically difficult study with suboptimal image quality. Due to high probability of infective endocarditis (IE), a transoesophageal echocardiogram (TEE) was obtained. TEE revealed aortic valve vegetation associated with moderate aortic regurgitation. Also, there was mitral valve vegetation complicated with valve abscess formation, valve perforation and moderate mitral valve regurgitation (figure 1 , video 1 ). The decision for treatment of this patient was decided by a multidisciplinary team of physicians along with the patient's family. Given the extremely high mortality risk of surgery, the patient's poor baseline functional status and her neurological deterioration, it was decided that the patient was not a surgical candidate and would be managed medically.

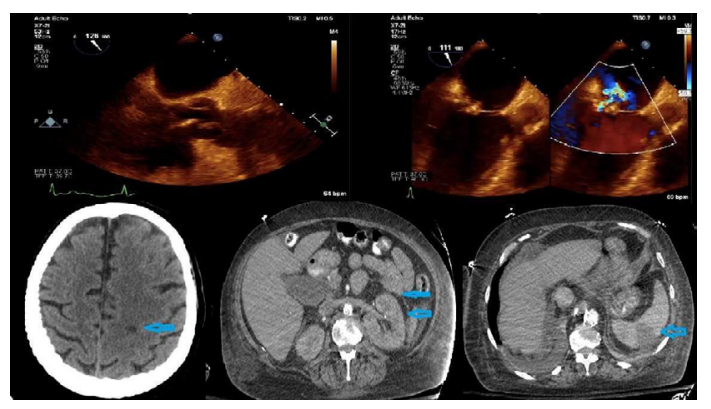

Figure 1 Top left: transoesophageal echocardiogram (TEE) — a large vegetation noted attached an aortic valve leaflet. Top right: TEE long axis view; posterior mitral leaflet has a vegetation with a focal tissue dropout and regurgitant jet. Bottom left: CT of the head revealing a hypodense lesion in the right parietal region. Bottom middle: CT of the abdomen revealing multiple hypodense lesions of the left kidney. Bottom right: CT of the abdomen showing a wedge-shaped hypodensity of the spleen.

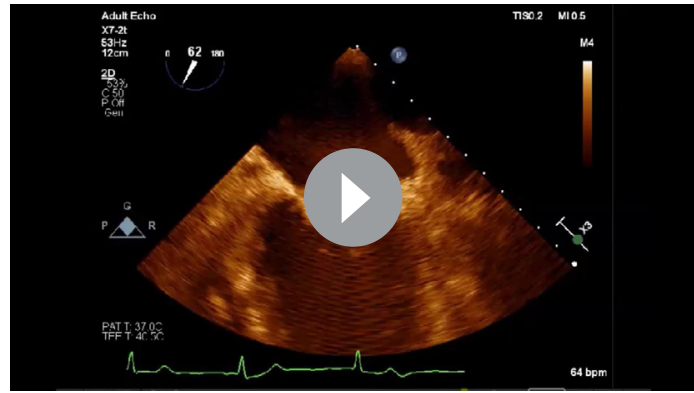

Video 1 1st frame: TEE long axis of aortic valve revealing an echogenic density with independent mobility attached to the aortic valve leaflets on the aortic side. 2 nd frame: TEE color Doppler interrogation revealing the presence of moderate eccentric aortic regurgitation. 3 rd frame: TEE mitral valve commissural view; revealing a $1.7 \times 1.5 \mathrm{~cm}$ echogenic mass attached to the posterior leaflet on atrial side with independent mobility, with echolucency present. 4 th frame: TEE long axis view showing a large vegetation on the mitral valve with associated perforation and associated regurgitation. 5th frame: 3D TEE; surgical view; revealing an echogenic mass attached to the P2, P3 scallops of the mitral valve.

IE is a life-threatening disease affecting 3-7/100 000 patients per year. ${ }^{1}$ While many pathogens can cause IE, Staphylococcus aureus has become the most common cause in the industrialised world due to the increase in healthcare- associated infections. ${ }^{1}$ TTE is recommended in all patients with suspected IE to identify vegetation, assess ventricular and

\section{Learning points}

- A high level of suspicion for infective endocarditis (IE) in septic patients with Staphylococcus aureus bacteraemia is essential as these patients typically suffer high morbidity and mortality. The use of an interdisciplinary medicine team including infectious disease specialists is recommended.

- Multimodal imaging is essential in the diagnosis of IE as the disease and its complications can often be missed with initial imaging studies. Transthoracic echocardiogram is a far more superior imaging modality in the diagnosis of IE

- Multimodal imaging for detection of extra cardiac complications is essential as this can significantly alter management. It is important to use appropriate studies in these patients and be familiar with the indications for early surgical intervention. 
valvular function, as well as to detect complications. ${ }^{2}$ Due to high risk of IE in patients with Staphylococcus bacteraemia, TEE is reasonable even if initial TTE does not show evidence of endocardial infection. TEE has much higher sensitivity than TTE in detecting vegetation $\left(90 \%-100 \%\right.$ vs $40 \%-63 \%$, respectively). ${ }^{3}$ In addition, TEE is more effective at detecting complications of MSSA IE. Common complications include regurgitation, leaflet perforation, perivalvular abscess and fistula formation. ${ }^{3}$ The sensitivity and specificity of TTE is $45 \%$ and $98 \%$, respectively in detecting perforations ${ }^{4}$ and $28.3 \%$ and $98.6 \%$ in detecting abscess. $^{5}$ Conversely, TEE has a sensitivity and specificity of $95 \%$ and $98 \%$ for perforations, ${ }^{4}$ and $87 \%$ and $94.6 \%$ for abscess detection. ${ }^{5}$ These discrepancies highlight the importance of multimodal imaging in the diagnosis and further evaluation of this disease.

Once the diagnosis is confirmed with Modified Duke Criteria, it should be evaluated and managed with consultation of a multispecialty team including an infectious disease specialist, cardiologist and cardiac surgeon in selected cases. ${ }^{2}$ Initial treatment requires prolonged antibiotic therapy tailored to specific pathogens. Nafcillin is commonly used against MSSA for a duration of 6 weeks once blood cultures clear. ${ }^{1}$ Surgical intervention is indicated in the following instances, including valve dysfunction resulting in symptoms of heart failure, left-sided IE caused by $S$. aureus or other highly resistant organisms, heart block, abscess, destructive penetrating lesions and persistent infection after the onset of appropriate antimicrobial therapy. ${ }^{2}$ Due to the high mortality of MSSA IE, proper use of multimodal imaging and multidisciplinary medicine teams are of the most importance to ensure prompt diagnosis and effective treatment.

Contributors WK contributed by writing the manuscript, literature review and reviewing relevant imaging. $\mathrm{MO}$ contributed by editing the manuscript and reviewing relevant imaging. DZ aided in editing the manuscript, literature review, provided direct patient care and reviewed imaging. SS contributed by providing images/videos and editing the manuscript.

Funding The authors have not declared a specific grant for this research from any funding agency in the public, commercial or not-for-profit sectors.

Competing interests None declared.

Patient consent for publication Obtained.

Provenance and peer review Not commissioned; externally peer reviewed.

\section{ORCID iD}

Michael Omar http://orcid.org/0000-0002-5777-386X

\section{REFERENCES}

1 Baddour LM, Wilson WR, Bayer AS, et al. Infective endocarditis in adults: diagnosis, antimicrobial therapy, and management of complications. Circulation 2015; 132:1435-86

2 Nishimura, R, Otto C, Bonow R, et al. 2014 AHA/ACC guideline for the management of patients with valvular heart disease: Executive summary. Ciculation 2014;129.

3 Evangelista A, Gonzalez-Alujas MT. Echocardiography in infective endocarditis. Heart 2004:90:614-7.

4 De Castro S, Cartoni D, d'Amati G, et al. Diagnostic accuracy of transthoracic and multiplane transesophageal echocardiography for valvular perforation in acute infective endocarditis: correlation with anatomic findings. Clin Infect Dis 2000;30:825-6.

5 Daniel WG, Mügge A, Martin RP, et al. Improvement in the diagnosis of abscesses associated with endocarditis by transesophageal echocardiography. N Engl J Med 1991;324:795-800.

Copyright 2020 BMJ Publishing Group. All rights reserved. For permission to reuse any of this content visit

https://www.bmj.com/company/products-services/rights-and-licensing/permissions/

BMJ Case Report Fellows may re-use this article for personal use and teaching without any further permission.

Become a Fellow of BMJ Case Reports today and you can:

- Submit as many cases as you like

- Enjoy fast sympathetic peer review and rapid publication of accepted articles

- Access all the published articles

- Re-use any of the published material for personal use and teaching without further permission

Customer Service

If you have any further queries about your subscription, please contact our customer services team on +44 (0) 2071111105 or via email at support@bmj.com.

Visit casereports.bmj.com for more articles like this and to become a Fellow 